\title{
Study of structure formation in bitumen-mineral compositions based on fly ash under water saturation
}

\author{
Lebedev Mikhail Sergeevich \\ High Technology Center \\ Belgorod State Technological University named after V.G. \\ Shoukhov \\ Belgorod, Russia \\ michaelL1987@yandex.ru
}

\author{
Chulkova Irina Lvovna \\ Department of construction materials and special \\ technologies \\ Siberian State Automobile and Highway University \\ Omsk, Russia \\ chulkova_il@sibadi.org
}

\begin{abstract}
The industrial powder waste from thermal power plants such as fly ash is used as asphalt or mineral filler due to its properties and dispersibility. However, the conflicting data on the fly ash usage are due to the different compositions, dispersibility, reaction capacity of the used fly ash. This paper presents the detailed research of the structuring process in bitumen-mineral compositions experimentally studied under the water saturation tests. The water saturation for the asphalt cements evaluates the strength of adhesion of the binder film to the particle surface as well as the stability of the bitumen-mineral structure when saturating water under the reduced pressure and elevated temperature. Depending on the fly ash composition, the structure formation operates differently at the component cohesion stage and during the swelling test. In bitumen-mineral composites, based on the high-lime ash, the mineral hydration leads to the binder film liftoff as well as to the change of the ash phase composition due to the low adhesion of bitumen and mineral particles. That results in undesirable formations in the system such as calcium sulfate dihydrate and ettringite, particularly. These formations cause the structural softening and the swelling of asphalt cements. The higher bitumen - low-lime ash adhesion provided the more stable structure of asphalt cements under testing. That resulted just in the binder film deformation without its liftoff. The swelling of the bitumen compositions was provided by the low packing density of ash particles in the asphalt cement.
\end{abstract}

Keywords - the thermal power plant fly ash, swelling test; asphalt cement; structure formation; new formation.

\section{INTRODUCTION}

Fly ash (FA) from thermal power plants (PP) is perfectly used as fillers for construction materials and for bitumenmineral composites and asphalt concrete, in particular. A distinguishing feature of the fly ash is high dispersibility, which provides the opportunity to use it in the same state as it was supplied without additional costs for fine grinding. It is reasonable that the use of the fly ash waste for bitumen concrete compositions was studied worldwide, and the extensive experience in the fly ash usage has been gained so far [1-5]. However, there is no consensus on the issue how that disperse material impacts the quality of the bitumenmineral composites. For example, in study [6] it was found that due to the extended surface, the organic binder film had the ordered supermolecular structure, higher density and aging resistance than those of the composites with the conventional lime stone. As a result, that asphalt concrete demonstrated high physical and mechanical properties, such as thermal and water resistance. The further experience in using the fly ash waste is also presented in [7-9]. The results of other studies $[1,2,10]$ demonstrated that adding the fly ash into the composites increased the bitumen consumption because of the lower structuring in comparison with pure carbonate powders. The asphalt concrete gained higher water saturation, lower water and compression resistance under $50{ }^{\circ} \mathrm{C}$.

The mentioned controversial data are to be explained by the differences in composition, dispersity and reactivity of the used fly ashes. These characteristics are crucial for the efficient use of industrial powder waste in bitumen-mineral compositions and asphalt concrete. Using two samples of fly ash with different calcium lime content in research [11], the significant difference in structuring and physical and mechanical properties of bitumen-mineral composites was revealed due to the impact of phase and sizing characteristics (the composition and the dispersity, respectively) of powders. It was found that adding the low-lime ash required more bitumen and demonstrated lower durability of the composition. However, the low-lime ash revealed higher bitumen absorption which increased the structural stability of the bitumen-mineral composite. When using the high-lime ash, the binder film over the surface of particles was destructed by water due to the low absorbing capacity which led to the structural liftoff. The current paper studies the structuring processes in bitumen-mineral compositions under water saturation.

\section{EXPERIMENTS}

\section{A. Materials}

The experiments were provided using two types of fly ash: the high-lime FA from the Nazarovskaya hydro-power plant (Nazarovo, Krasnoyarsk Territory, Russia) and the low-lime FA from the Omskaya power plant - 4 (Omsk, Russia). The BND 60/90 oil bitumen with the penetration of 60 . For each FA type, an optimum mix was experimentally composed where the water saturation for compacted cylindrical 
specimens of the bitumen-FA mixture was 4-5\%. In the composition with high-lime fly ash, the bitumen weight fraction was $18.5 \%$ over $100 \%$ of the disperse material, and $37 \%$ - for the low-lime FA composition [11].

\section{B. Research Techniques}

The specimens of bitumen-mineral composites (asphalt cements) were obtained through the hydraulic compression of the bitumen-fly ash mixture under the pressure of $10 \mathrm{MPa}$ in metal moulds in accordance with the R 52129-2003 Federal standard [12]. Each cylindrical specimen was $25 \mathrm{~mm}$ in both diameter and length. Three specimens of the predefined bitumen - fly ash compositions were prepared for the swelling test. The next day after preparation, the specimens were weighed in air as well as in water under the temperature of $20 \pm 2{ }^{\circ} \mathrm{C}$. Then, the specimens were placed into a vacuum device with water under the temperature of $20 \pm 2{ }^{\circ} \mathrm{C}$ and kept under the constant pressure up to $0.002 \mathrm{MPa}$ for an hour. Then, the specimens were kept for another 30 minutes under the pressure increased up to the atmospheric. Next, the specimens were placed for 4 hours into a liquid thermostat under the temperature of $60 \pm 2{ }^{\circ} \mathrm{C}$. Then they were placed again into a water container and kept for $16-18$ hours under the temperature of $20 \pm 2{ }^{\circ} \mathrm{C}$. At the end of experiment, the specimens were weighed in air and water. The swelling value of asphalt cement specimens was calculated as follows

$$
S=\frac{\left(m_{2}-m_{3}\right)-\left(m-m_{1}\right)}{m-m_{1}} \cdot 100 \%
$$

where $m$ and $m_{1}$ - specimen weights before the experiment in air and water, respectively; $m_{2}$ and $m_{3}$ - specimen weights after the experiment in air and water, respectively.

The swelling values were calculated as the mean value of the results of three simultaneously conducted tests.

The following techniques were used to study the processes in the systems to be tested, as well as to analyse the components formed during the tests.

- X-ray diffraction analysis (XRD) with the ARL 9900 WorkStation, Thermo Fisher Scientific, which combines full XRF and XRD capability. The identification of minerals was performed using the PDF-2, ICCD.

- infrared spectroscopy, using the Vertex 70 FTIR research spectrometer, Bruker Optics. The tablet-shaped specimens of the mixture with potassium bromide $(\mathrm{KBr})$ were tested for absorption within the mid infrared band of $370 \mathrm{~cm}^{-1}-4000$ $\mathrm{cm}^{-1}$.

- scanning electron microscopy, using the TESCAN MIRA 3 LMU electronic microscope.

\section{RESULTS AND DISCUSSION}

\section{Swelling of the bitumen-fly ash specimens}

Swelling tests of the bitumen-filler asphalt cements evaluate the binder adhesion to the surface of particles and, as a result, the absorbing capacity of a disperse filler as well as the structural stability of the bitumen-mineral materials which were water saturated under the decreased pressure and increased temperature. The test conditions evaluated the composite behavior in actual usage environment.

The swelling of the bitumen - fly ash asphalt cements was indicated by the volume change of a specimen. In that test, the characteristics such as volume, mean density and water saturation of the bitumen-mineral composites were calculated. Table 1 presents the dynamics of the results obtained since the water saturation experiment is a part of the swelling test (the thermal control up to $60 \pm 2{ }^{\circ} \mathrm{C}$ ).

TABLE I. STRuctural CharaCteristics of AsPhalt CEMENTS UNDER TESTING

\begin{tabular}{|l|c|c|}
\hline \multicolumn{1}{|c|}{ Characteristics } & $\begin{array}{c}\text { High-lime fly ash from } \\
\text { the Nazarovskaya } \\
\text { hydro-power plant }\end{array}$ & $\begin{array}{c}\text { Low-lime fly ash from } \\
\text { the Omskaya power } \\
\text { plant-4 }\end{array}$ \\
\hline $\begin{array}{l}\text { Mean density of asphalt } \\
\text { cement before test, } \\
\mathrm{kg} / \mathrm{m}^{3}\end{array}$ & 2057 & 1528 \\
\hline $\begin{array}{l}\text { Mean density of asphalt } \\
\text { cement after water } \\
\text { saturation under R } \\
\text { 52129-2003 Federal } \\
\text { standard [12], kg/m }\end{array}$ & 2098 & 1562 \\
\hline $\begin{array}{l}\text { Water saturation, } \\
\text { volume \% }\end{array}$ & 4.9 & 4.4 \\
\hline $\begin{array}{l}\text { Swelling after water } \\
\text { saturation, volume \% }\end{array}$ & 0.4 & 0.6 \\
\hline $\begin{array}{l}\text { Mean density of asphalt } \\
\text { cement after swelling, } \\
\text { kg/m }{ }^{3}\end{array}$ & 2083 & 1576 \\
\hline $\begin{array}{l}\text { Water saturation in } \\
\text { swelling, volume \% }\end{array}$ & 9.8 & 7.6 \\
\hline Swelling, volume \% & 3.4 & 1.75 \\
\hline
\end{tabular}

As Table 1 shows, the density of composites under the water saturation increased as the pores were water-filled. That occurred in both composites. The volume increase was just 0,4 and $0,6 \%$. When swelling, the water saturation ratio, as well as the volume change, increased due to the continuous water penetration into specimens. The water saturation resulted in about a twofold increase (up $4.9 \%$ to $9.8 \%$ for the fly ash from the Nazarovskaya hydro power plant, up $4.4 \%$ to $7.6 \%$ for the fly ash from the Omskaya power plant). The volume increase for the high-lime ash was 3.4\% which overran the R 52129 2003 Federal standard [12] $(3.0 \%)$ and was about twice as high as the volume change of the low-lime FA from the Omskaya power plant $(1.75 \%)$. The difference between the density change of the bitumen-mineral composites for both mixtures is to be noticed: when the density value in the lowlime FA composites demonstrated a continuous increase, the density for the high-lime fly ash composites decreased in relation to the density after the water saturation. In the latter case, some disintegration of the binder structure can be implied.

The differences mentioned above revealed that the structuring proceeded differently at different stages: at the stage when constituents were combined and under the swelling test. The bitumen-mineral composition with the highlime fly ash probably indicated the phase composition changes as a result of the activated mineral hydration which provided 
the decrease of the composite density as well. The changes in the low-lime FA asphalt cement are unlikely to occur.

\section{Research of the changes in fly ash and asphalt cement compositions by $X$-ray diffraction analysis}

The XRD diagrams of the asphalt cement specimens after the swelling were compared to the XRD diagrams of the initial fly ash. This is due to the fact that only the fly ash crystal phases demonstrated the pronounced reflection peaks whereas the bitumen structure is amorphous. When those materials are combined, there are no changes in the phase composition revealed.

The study of the system based on high-lime fly ash revealed the changes in a mineral part. It is likely that the bitumen film liftoff with the surface of particles occurred due to the low absorption of the filler under decreased pressure and increased temperature. That caused the activated mineral hydration as well as the new formation in the system. Based on the XRD data, particularly, on the peak intensity, the content of free lime and tricalcium aluminate decreased while the concentration of portlandite (as the product of the free lime hydration) and calcite increased. In addition, the reflection of calcium sulfate dihydrate (as an anhydrite hydration product) and ettringite (as a result of the tricalcium aluminate hydration and the anhydrite hydration) were detected (Figure 1). The appearance of two latter sulfate minerals was due to the anhydrite subsolution. The growth of crystal formations was probably provided by water curing of the specimens with the water temperature of $60{ }^{\circ} \mathrm{C}$ (according to the test technique). The new formations such as ettringite caused the volume increase of a specimen.

There were predictably no changes in the mineral composition of the low-lime FA as it consisted of the water resistant phases which could not be solved and transformed even under the hot water curing (Figure 2). Moreover, the bitumen film adhesion to the particles of that fly ash was much higher which preserved it on the bottom layer. The detection of sassolite in the XRD diagrams of the bitumen-mineral compositions was due to the contamination of specimens with that product at the preparation stage.

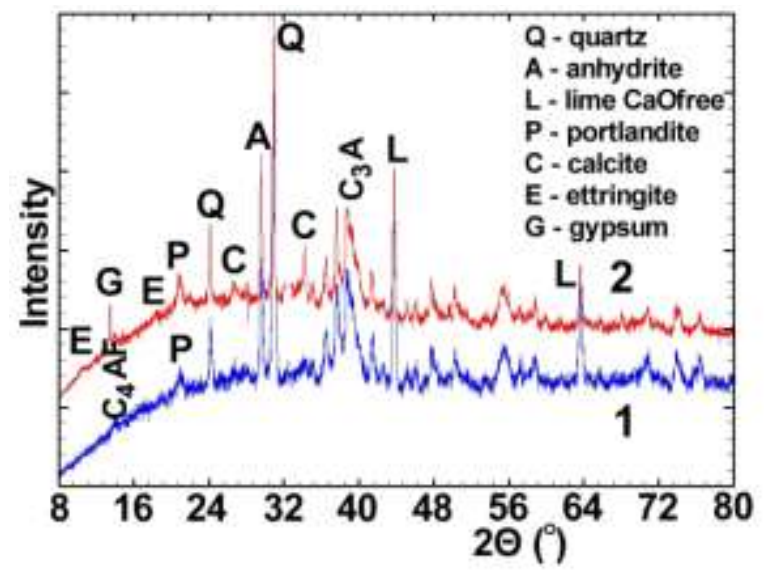

Fig. 1. XRD diagrams of the high-lime FA from the Nazarovskaya hydro power plant (1) and the high-lime FA-based asphalt cement after swelling test (2)

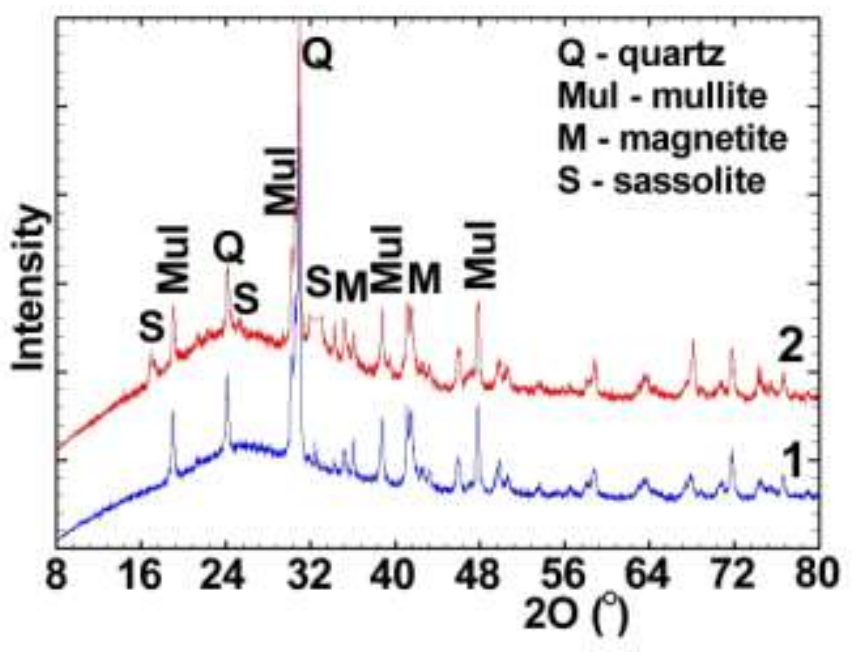

Fig. 2. XRD diagrams of the low-lime FA from the Omskaya power plant (1) and the low-lime FA-based asphalt cement after swelling test (2)

\section{E. Research of the changes in the fly ash and asphalt cement compositions using the infrared spectroscopy}

The research of the structuring, using the infrared spectroscopy, requires the basis which is used as a template to compare the studied system spectra after the swelling test. The source fly ash was chosen for comparison, as in the case with XRD analysis. It should be noticed that, when mixing the fly ash with bitumen, some intensities and the profile broadening of the absorption bands were identified in the infrared spectra. That could be explained by activating the certain groups of minerals and chemical bonding in the thin layer between the bitumen and filler molecules. However, the absorption bands, which identified a new formation, were not detected in that case.

The results obtained using the IR spectroscopy confirm the content of new formations in the bitumen-mineral composite based on the fly ash from the Nazarovskaya hydro power plant after a swelling test (Figure 3). For example, the absorption bands of $\mathrm{CO}_{3}{ }^{2-}$ in calcite structure (1420 and $\left.877 \mathrm{~cm}^{-1}\right), \mathrm{SO}_{4}{ }^{2-}$ (about $\left.1113 \mathrm{~cm}^{-1}\right), \mathrm{OH}$ group in gypsum $\left(1623,3560 \mathrm{~cm}^{-1}\right)$, as well as ettringite $\left(1646,1678,3417\right.$ and $3640 \mathrm{~cm}^{-1}$ (the latter band can be related to portlandite) [13], were detected in the asphalt cement specimen. Therewith, decreasing the relative intensity (the spectra were normalized in the band of 1110 $\mathrm{cm}^{-1}$ which can be related to $\mathrm{Si}-\mathrm{O}$-non-bridging bonds in quartz and alumina silicate glass phase as well as to $\mathrm{SO}_{4}{ }^{2-}$ sulfate ion) of the absorption bands for the tricalcium aluminate $\left(780,720,510,470,420 \mathrm{~cm}^{-1}\right)$ was noticed. The decrease in the amount of tricalcium aluminate was revealed by the XRD. The reduction of free lime in the middle IR band is hardly possible to be detected as the $\mathrm{Ca}-\mathrm{O}$ oscillations are detected with lower wavenumbers.

The IR spectrum of the fly ash from the Omskaya power plant and the asphalt cement based on that low-lime FA were not significantly changed before and after testing (Figure 4). That proved the arguments for the higher stability of the bitumen-mineral structure under water saturation and swelling (swelling was 1.75 of volume \%) 

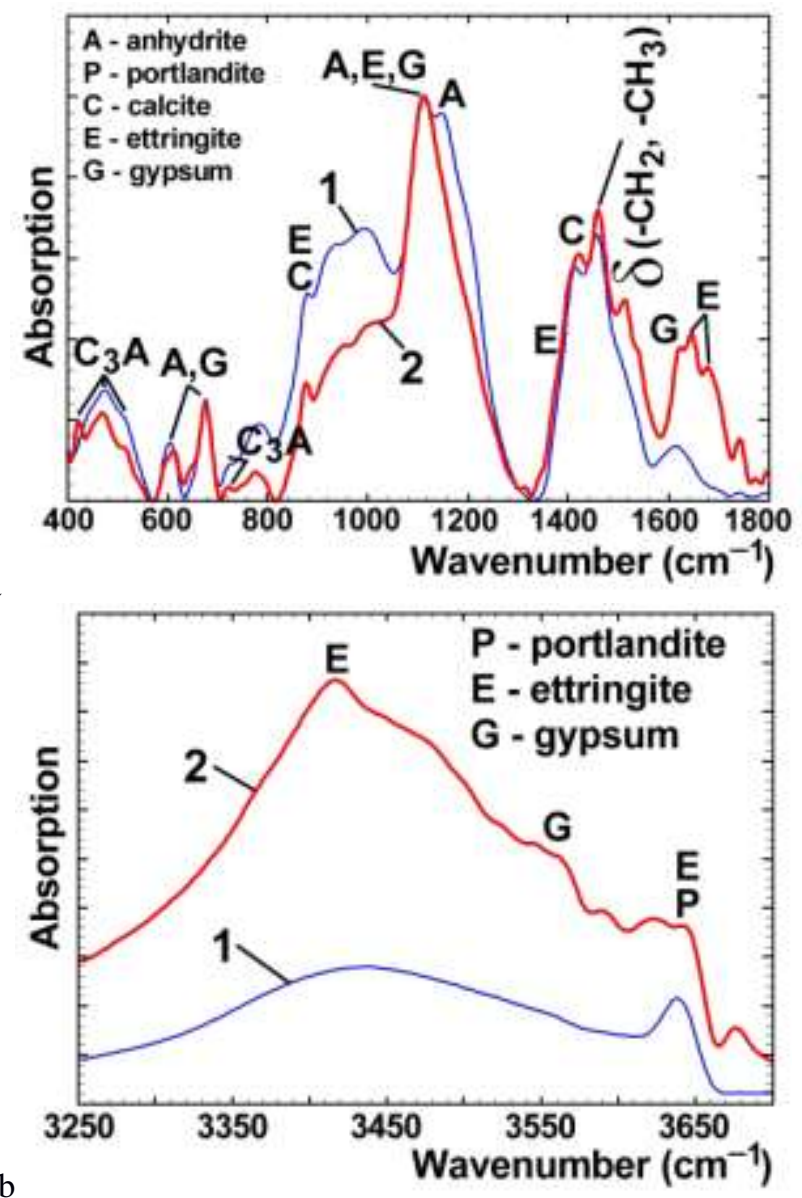

non-uniformity in the high-lime FA-based asphalt cement was detected after the swelling test: there were areas covered by the bitumen film as well the areas not covered, where new formation occurred (Figure 5a). That confirmed the suggestion of the low binder-particles adhesion, which resulted in the bitumen film liftoff under water impact. The morphology of new formations indicated the ettringite (Figure 5b) shaped as oblong hexagonal prisms (the cross sections of some formations revealed the $\left[\mathrm{Al}(\mathrm{OH})_{6}\right]^{3-}$ octahedron structure of ettringite [13]) and the gypsum (Figure 5c) in the shape of centrosymmetric crystals. Considering the dimensions (up to $500 \mathrm{~nm}$ in diameter), most part of ettringite was noticed to be $\mathrm{X}$-ray amorphous which resulted in its weak reflection in $\mathrm{X}$ ray diagrams (Figure 1).

Studying the specimens which contained the fly ash from the Omskaya power plant, one could observe a slight volume increase under the swelling test. That increase took place due to the low packing density of the FA particles in the asphalt cement's structure. That disperse material, however, had a certain absorption capacity sufficient enough to prevent the bitumen film disintegration under the hot or cold water curing for a long time (Figure 6). It should be noticed that structure of the bitumen-mineral composite based on the high-lime FA revealed completely different properties (Figure 5). The observed wavy structures could be explained by the deformation of the bitumen film which caused by the test conditions (Figure 6).

Fig. 3. IR spectra of the high-lime fly ash from the Nazarovskaya hydro power plant (1) and the asphalt cement based on it after swelling test (2): a «fingerprint area»; b - shortwave IR zone

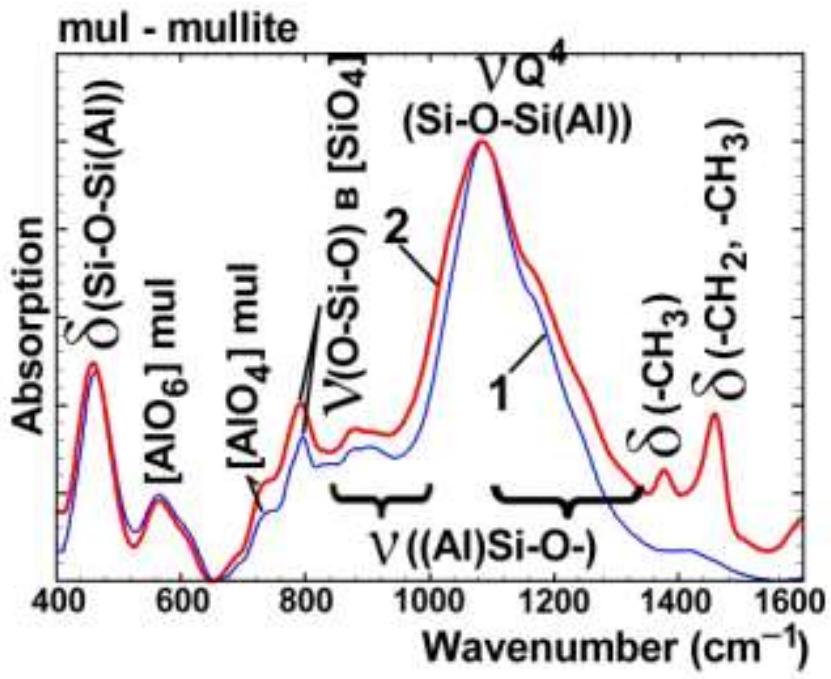

Fig. 4. IR spectra of the low-lime fly ash from the Omskaya power plant (1) and the asphalt cement based on it after swelling test (2)

F. Research of the changes in the fly ash and asphalt cement compositions using scanning electron microscopy

The results obtained with the electron microscope completely agree with the XRD and IR spectroscopy data. A 

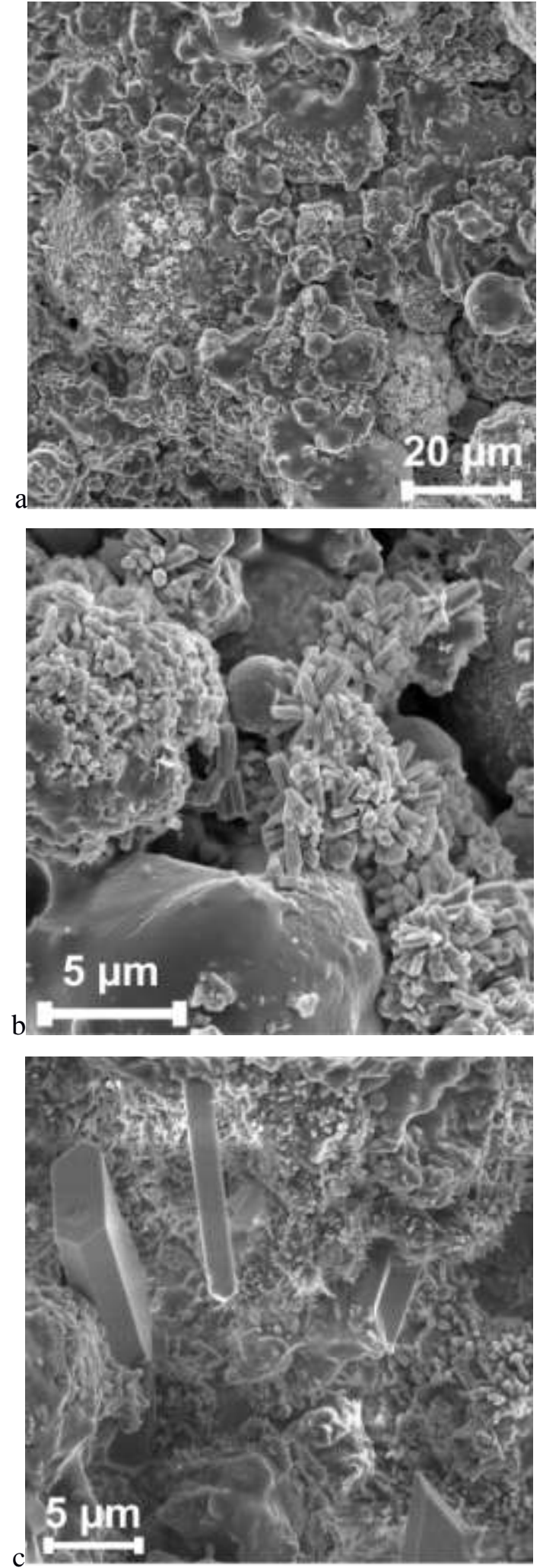

Fig. 5. Microstructure of the high-lime FA-based asphalt cement after the swelling test: $\mathrm{a}$ - overall view; $\mathrm{b}, \mathrm{c}-$ new formations in the composite structure
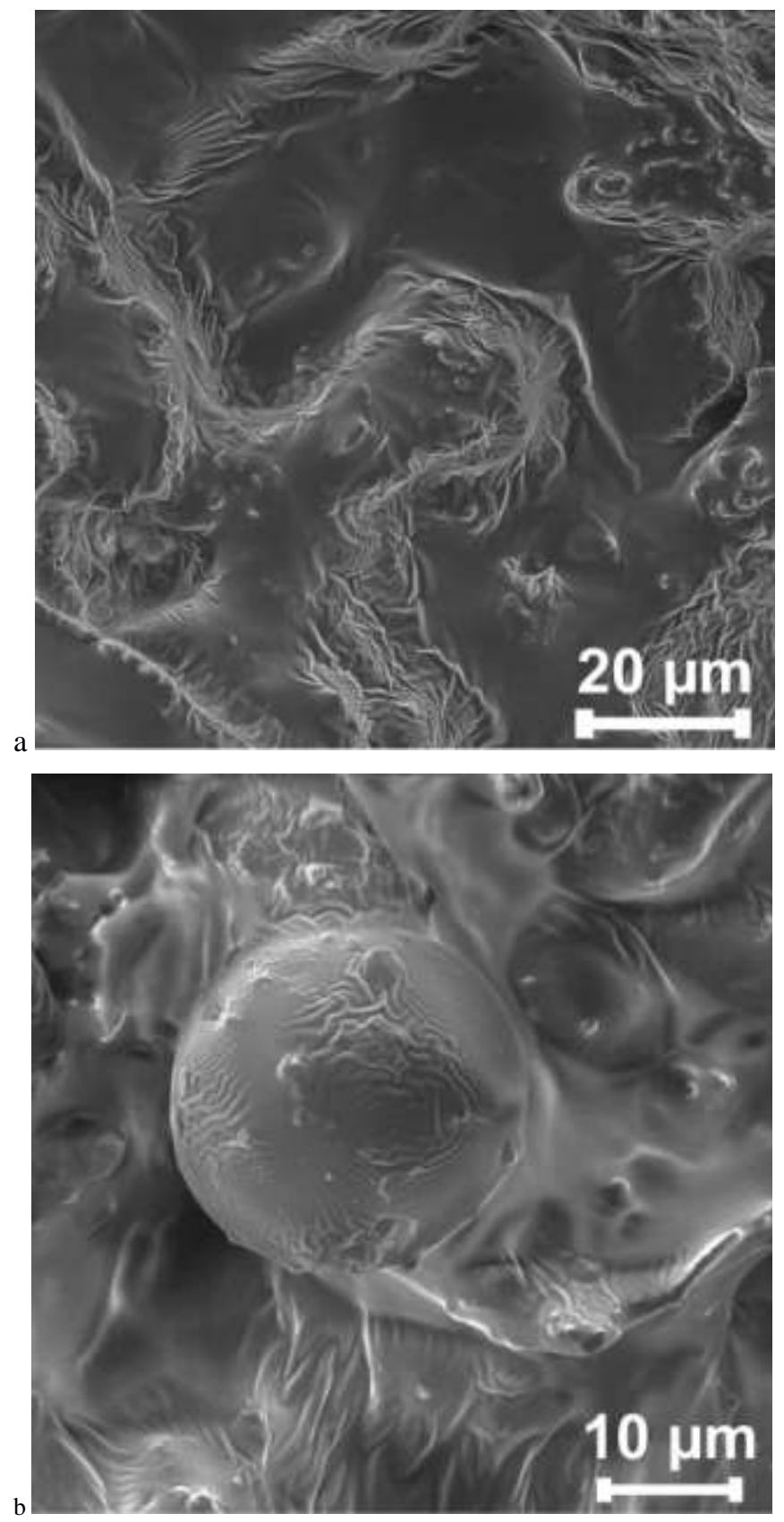

Fig. 6. Microstructure of the low-lime FA-based asphalt cement after the swelling

\section{CONCLUSION}

The swelling experiment for the specimens of the bitumenfly ash mixtures was studied in this paper. The experiment evaluates both the adhesion of binders to the particles as well as the absorption capacity of the disperse filler and the changes in the bitumen composite structure during the water saturation under decreased pressure and increased temperature. The test conditions provide the opportunity to evaluate the composite behavior in actual working environment. According to the results obtained, the specimens based on the low-lime fly ash revealed the lower rate of the 
volume increase, which is due to the water resistance of the FA particles and the bitumen adhesion to the particles surface. The high-lime FA revealed lower bitumen adsorption which led to the partial liftoff of the bitumen film and fly ash particles. Due to the water activated minerals in the FA, the new undesirable formations, such as calcium sulfate dihydrate (gypsum) and ettringite, are generated in the system as a result of hydration. It was proved by several research techniques, i.e., XRD, infrared spectroscopy and scanning electron microscopy, that such structural changes caused the volume increase by $3.4 \%$ and some softening of the composite structure as well.

\section{Acknowledgment}

This research work is financially supported by the Ministry of Education and Science of the Russian Federation in the framework of State Assignment №11.9329.2017/8.9, the Russian Federation Ministry of Education and Science in the framework of Presidential Scholarship № PS-2099.2015.1, using equipment of High Technology Center at BSTU named after V.G. Shoukhov.

\section{References}

[1] E. Putilin, V. Tsvetkov. The use of fly ash and ash and slag waste in road construction: revision of national and international experience in using the solid fuel combastion wastes from power plants. Moscow, 2003, p. 60.

[2] N. Yarmolinskaya, L. Tsupikova. Corrosion resistance improvement of asphalt concrete on the base of waste from power plants. Stroyitelnyie materialy, Nr. 9, pp. 46-47, 2009.
[3] F.V. Zimmer, "Fly Ash as a Bituminous Filler," Proceedings of the Second Ash Utilization Symposium, 1970, pp. 49-76.

[4] "Utilisation des déchets et sous-produits en technique routière, Organisation de coopération et de développement économiques," Groupe de recherche routière, 1977, p. 179.

[5] A. Simms Scott, "Use of coal fly ash in asphalt concrete mixes," DalTech-Dalhousie University, 1998, p. 148.

[6] G. Rasstegayeva. Active and activated mineral powders produced from industrial waste. Voronezh. 2002, p. 192.

[7] M. Jovanović, A. Mujkanović, A. Šeper, "Mechanical properties of bituminous aggregate mixture BNS 22A prepared with fly ash from power plant "GACKO" as a filler replacement," $15^{\text {th }}$ International Research/Expert Conference "Trends in the Development of Machinery and Associated Technology" TMT 2011, Prague, Czech Republic, 12-18 September 2011, pp. 221-224.

[8] K.Sobolev, F. Ismael, J.Bohler, A. Faheem, A.Covi, "Application of Fly Ash in ASHphalt Concrete: from Challenges to Opportunities," World of Coal Ash Conference, Session: Cement \& Concrete VI, April 2013.

[9] K. Sobolev, F. Ismael, R. Saha, N.M. Wasiuddin, N.E. Saltibus "The effect of fly ash on the rheological properties of bituminous materials," Fuel, 116, pp. 471-477, 2014.

[10] L. Urkhanova, A. Bituyev. The use of fly ash from the Gusinoozerskaya hydro power plant as mineral powder for asphalt concrete, $4-26$, pp. $60-$ 65, 2012.

[11] M.S. Lebedev, N.I. Kozhukhova, I.L. Chulkova, "Effect of phase and size characteristics of fly ash from power station on properties of bitumen composites," IOP Conf. Series: Materials Science and Engineering, 222, pp. 012005, 2017.

[12] R 52129-2003 Federal standard on mineral powder for asphalt concrete and organic and mineral blends. Moscow. 2004, p. 25.

[13] D. Lucia Fernández-Carrasco, L.M. Torrens-Martín, Morales and Sagrario Martínez-Ramírez, "Infrared Spectroscopy in the Analysis of Building and Construction Materials, Infrared Spectroscopy," Materials Science, Engineering and Technology, Prof. Theophanides Theophile (Ed.). 2012. 